\title{
Research Study on Significance of Gamification Learning and i-Campus Using Internet of Things Technology-Enabled Infrastructure
}

\author{
Veeramanickam Murugappan, \\ Debnath Bhattacharyya and Tai-hoon Kim \\ Additional information is available at the end of the chapter \\ http://dx.doi.org/10.5772/intechopen.75744
}

\begin{abstract}
In this chapter, we discusses the importance of smart i-campus in educational institutes and gamification-based learning to be an integral part of the Internet of Thing (IoT) enabled the smart campus to explain its significance in terms using modern technology in teaching and learning. This research study related to two dimensions different fields, one perspective on fully engaged and enthusiastic learners from gamification part and another perspective on enhanced technology accessibility for the dream i-campus will pretend to be realistic in the near future. Analytical study of smart campus architecture with all features includes classroom laboratories... etc... And the gamification significance in terms of knowledge transfer, assessments, microlearning, competition among learners, to engage maximum level, rewards on achievements. It's emphasis on the need for both approaches in a single platform to the learners for efficient and smart learning environments to set up.
\end{abstract}

Keywords: gamification learning, internet of things, smart campus, e-learning

\section{Introduction}

In a modern day as technologically advanced in all domains related to mankind, so very important to concern about the need of the hour to utilize modern technologies in traditional classroom and college campus in term of attracting students with the internet of things enabled smart campus. In future, any academic institutes need to adopt such technologies without 
any choice of away from modern world necessity, especially in teaching and learning system. Today so many challenges as we have a different way of learning so teaching becomes unconcerned because in many institute's modern infrastructures is lagging especially in Asian countries and developing countries. Students are in the speedy world using internet maximum timing. So this increased more opportunity to engage them gamification learning mode easily to any individual learners thinking methods and to progress in their various skills, it was quite difficult to engage them in the traditional classroom campus become challenging factors.

In academics, lecturers are compelled to work on normal blackboard and chalk piece of teaching methods. To overcome this campus infrastructure needs to be enhanced in such way to adopt the internet of things platform based smart classrooms, smart campus, smart lab...etc. So it will help many students to enhance the professional way and in-depth academic way of performance with highly configured resource availability. For this, here we propose two major factors in terms higher engagement level will be addressed for more active learners and incorporate them to be part of smart campus maximum timings inside their institute's location. However, simply providing smart, modern campus is not enough to rectify this problem so need of gamification e-learning platform model vital within the campus network. While various factors are concerned to modernize smart campus, but this research study took major factors concern to improve efficiency in terms of engaging student learners in improving their focus on learning and being inside the campus for a longer duration to part various learning models and assessments toward gamification functionalities.

As per Table 1 from HP estimation, they conducted the survey, all prediction figures are drastically increasing over a period of time and the results are quite surprising factors to understand the need for modern infrastructure in academic Campus too. So global level all fields are moving toward for completely automated is understandable. " $43 \%$ IoT data processing at done before sent to cloud data center, 38\% application's data have economic impact on which it required interoperability between one IoT platform to another systems, $85 \%$ of industry will adopting IoT platform by 2019." [1] So many devices help to link among the physical world and digital platform to progress life of productivity, highly skilled society and maximum automated smart industries and their products finally a great platform to Produce skilled workers more knowledge with highly engaged to be part of growth for the country. Smart homes are gradually trending among all builders; construction to provide people with a comfortable zone level of high technologies enhanced smart homes. Wearable's devices rapidly

\begin{tabular}{ll}
\hline Year wise & Number of connected devices (IoT) \\
\hline 1990 & 0.3 Million \\
1999 & 90.3 Million \\
2010 & 5.0 Billion \\
2013 & 9.0 Billion \\
2025 & 1.0 Trillion \\
\hline
\end{tabular}

Table 1. Connected devices estimation [1]. 


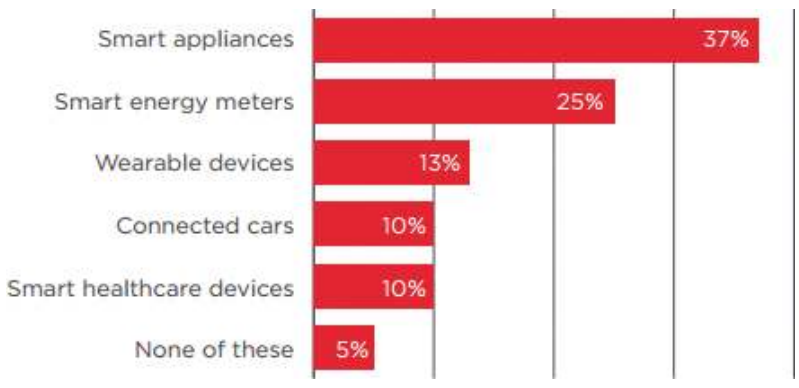

Figure 1. Customer's connected device preferences: Source GSMA report [2].

increasing among students and adult user's usage level need to be considered to utilize in gamification platform to connect applications with user's real-world environments.

As Figure 1 about GSMA study finds customers interest for possible connected device they likely to use for home appliance [2]. As Campus modernization is very important in Smart Campus for academic institutions so usage of Internet of Things (IoT) becomes evidently are important across the globe and all colleges and institutes need to prepare for data collection from different sets of sensors, smart device applications and various platforms of technologies, which insist on upgraded more efficient network model. Future i-campus using connected devices turn out to be a collection of sensors, big data application and data analytics for prediction, and other application of IoT technologies to make enhanced smart campus.

\section{Gamification in learning platform: study}

As a part of routine life, games not only entertain users, but also represent their behaviors also. The same can be used in e-learning by applying crux to learn and get a maximum number of the process. The techniques in games tend to provide simplification to learning approaches. The customization of e-learning processes with this approach can make it easy as ever. It is the use of gameplay mechanics used for Non-game applications where any process can be gamified. Its main goal is to engage learners by using gamification techniques in routine Teaching-Learning Processes. By keeping attention to the integration of tasks, we can motivate learners too [3].

To engage users in learning gamification is an efficient approach which can make content more attractive. B.J. Fogg argues that people respond to computers as they were persons, especially when gaming. To trigger certain behavior, it needs to be motivated. Gamification also extends the social interaction with other users. Fogg explains that when people perceive social presence, they naturally respond in social ways and have feelings of empathy or anger, or following social rules such as taking turns [3].

Gamification is mainly for usage of gamifying features in other than games, applications also, predominantly consumer is focused on the web-based the platform and mobile 
application too. Gartner Group predicts gamification will be a key trend that every CIO, IT planner and enterprise architect must be aware of as it relates to business. As the view of the gamified learning approach through a context-aware mobile learning environment, which gives motivation to students for learning by developing and implementing gamification strategies by using questionnaire with the help of a Smartphone and its functions. Pre and post-test results demonstrated that use of gamification increases the throughput of the overall process. Further, they revealed a positive relationship between learning achievement and motivation [4].

A game-informed approach being a learning activity, it recognizably uses game-like elements. The process of engaging new approaches to teaching and delivering personalized, context-sensitive content, via the game-informed, technology-supported, learning activities, has been reported to have significant beneficial effects on the academic outcomes of students in primary schools. Gamification still needs to pay attention to individual learners and their performances by using two approaches to learn the games and gamification of educational contents. Where learning for games refer to the use of digital games for learning purposes. Gamification is "the use of game design elements in non-gaming contexts" [4].

Personalized Gamification: In order to personalize gamification as: applications that are plugged into another application without being essential. Giroux et al. Describe epiphytic features as follows: i) such system cannot be existent without a host system, ii) the hosting system can able to exist without epiphyte iii) both can have independent presences in the network, and finally, such system cannot affects its hosting application [5].

As video games are becoming more popular among games, there is huge potential to use it for gamification of learning content. Social networking, gamification and traditional e-learning approaches are compared. Participants in novel approaches get better results concerning skill acquisition. The traditional approach yields better results for knowledge acquisition. Students' attitude toward the new tools is positive. Participation rates are low challenging assumptions found in current literature. With best use of social networking in e-learning, gamification is the use of game-thinking and playful design in non-game contexts, has only shown its potential as a motivational tool [6].

The effects of a gamification plug-in deployed in a learning management system were compared to those of a social networking site in the same educational setting. We found that both approaches presented better performance than a traditional e-learning approach in terms of academic achievement for practical assignments, but that, when it came to assessing knowledge, the traditional e-learning approach was better. Also challenging current assumptions, participation rates and scores remained low with the new tools, although students' attitudes were positive. [7] Even if there are many negative views toward games, there are great advantages and benefits of it to engage and incorporate features that are extremely compelling. Online learning is assessed using studying time. Numerous numbers of connections and many other parameters have its impact. IoT allows interaction among various physical spaces to learn the problem objectively and communicate among themselves. The connection between device endpoint to all users to make smart i-campus to produces effective campus outcomes [8]. 


\subsection{Gamification for campuses learning}

Major fact is objective in attempting to sustain good communications for supporting feedback and strengthening learning platform, instructors, student's users, this collectively interactive model between all users and good level of control features in gaming to engage users, helps to design ineffectual ways of fun learning [9].

- Duo Lingo: language learning from Web translates.

- Ribbon Hero: Teach how to use Microsoft Office and learning.

- Class Dojo: Class learning becomes Game of Rewards \& Feedback assessment

- Goal Book: Individual students learning Plans together

- The World Peace Game: Game-based Simulation for Classroom learning

- Coursera: Interactive Education from your Home

- Mr. Pai's Class: The Digitally Assistance for a Class

- Course Hero: Teacher and Student Interactions in Online

- Brain scape: Confidence on Basis of Repetition from games

- Socrative 101: Mobile interaction among Teacher \& Student [9]

\subsection{Top 10 productivity application uses gamification}

The main focus and practical usage of gamification toward help people their productivity plan and manageable task and challenges into reality. So the consistent way is to achieve it from the small goals [10].

- Habitica (HabitRPG)

- Super Better

- To-Doist Karma

- Epic Win

- Task Hammer

- Doable

- Chore Wars

- Mind Bloom

- Fitocracy

- Smarty Pig

- АВСуа

- FunBrain

- Carmen Sandiego [10] 


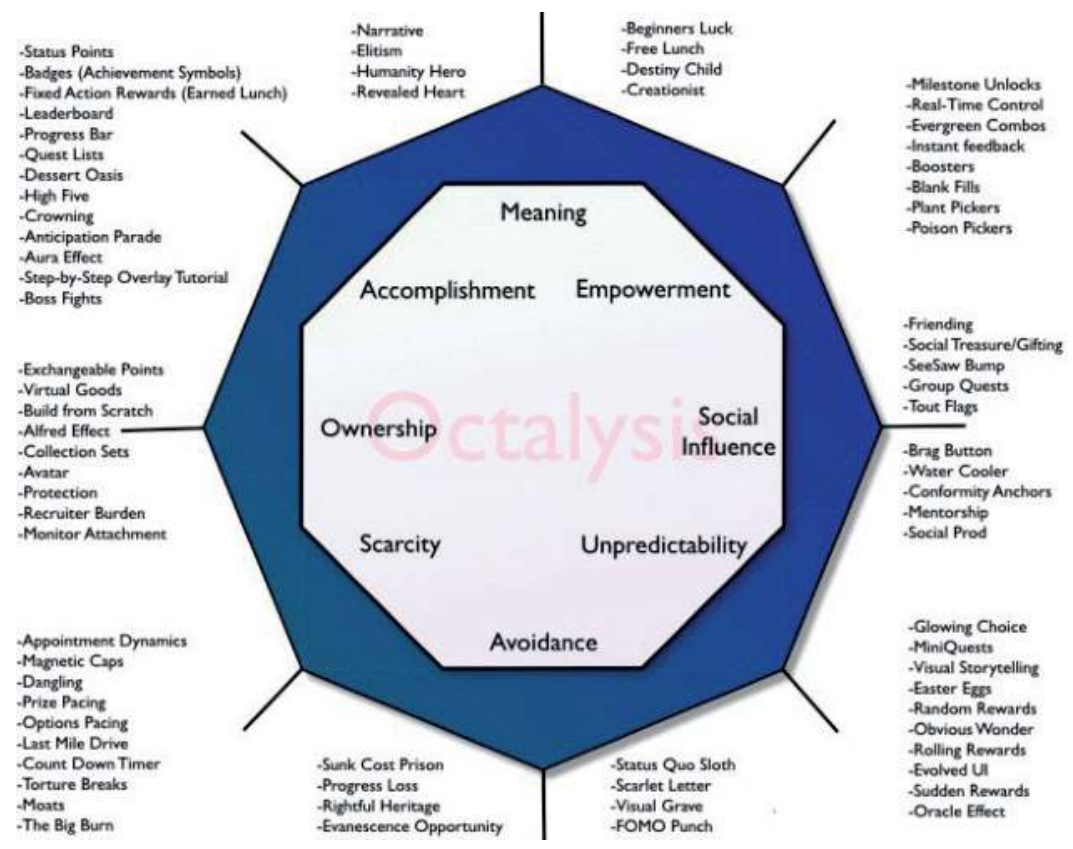

Figure 2. Gamification frameworks -Octalysis. [11].

Octalysis - Gamification Framework: Octalysis is Gamification Framework I shaped past 10 years of gamification-based research work. It's translated into nine languages globally and become necessary literature for Gamification model domain worldwide. [11] (Figure 2).

\section{Study of i-campus technologies}

As of June 2017, survey data from 138 educational institutions from the Center for Digital Education to conclude about the various projects of connected campus. To better understanding of about connected devices for i-campus. Queries like questions about education, user's engagement, and campus safety and network efficiencies.

The campus, which working on Smart i-campus is using numerous technologies using connected devices in the form of different domains. Dominant methods like classrooms with intelligence blended learning platform and digital signage.

This study clearly states that various models of smart technologies used in that $138 \mathrm{HE}$ institution like an Intelligent classroom, collaborative learning space, Data-driven decision-making and research work, Analytics of data, Cyber platform, signage digital oriented. Etc. But not listed on the gamification domain platform for learning model [12] (Figure 3). 
As digital signage come out at the top of second priority because technology is comparatively less expensive and very simple to implement. The objective of institutions to use signage like to include directing their students, to deliver weather data and news updates, information, provides an activity to engage users and post menus and major things are used for communication during an emergency situation. Smart lighting to automatically brighten for the presence of the populace and also can able to generate self-reports of its maintenance requirements and helps to improve energy efficiency.

As per experts predicts and expect the various outcomes from IoT like which includes for better accessibility for innovative resources, to increase the student engagement and to extend higher capacity in data analytic prediction. Some HE user's benefited from technology like experiencing from the IoT platform.

User's expectation from cost reduction, very but a few percents of the respondents realize about cost savings. In the same manner, $54 \%$ forecast for increasing capacity in data analytics platform and only $27 \%$ achieved in data analytics. As a major element of this smart campus is a data analytics toward explorations for benefits in more decision-making. Saving time expectation is higher in data management on the basis of streamlining data records (Figure 3).

As per CDE reports students getting more benefits from smart campus, teaching faculty and non-administrative too. So every new innovation from i-campus for classrooms and teaching tool for faculties are in terms of creating higher engagement to the experiences of all student users. And also for all stakeholders, the satisfaction level is good in i-campus new initiatives which are important for successes (Figure 4).

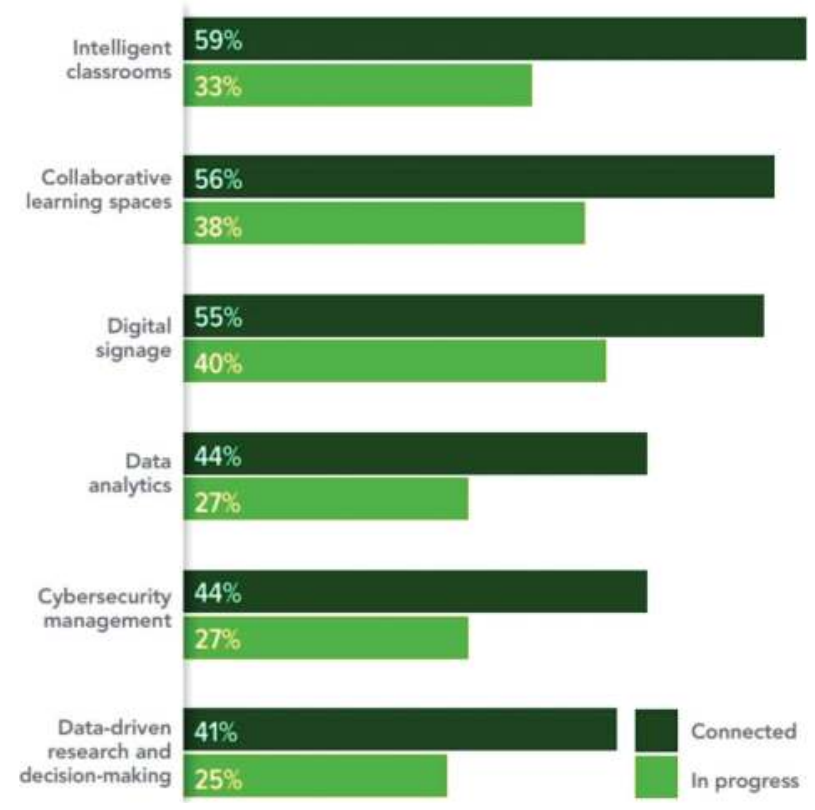

Figure 3. Smart technology usage: CDE surveys among 138 higher education [12]. 


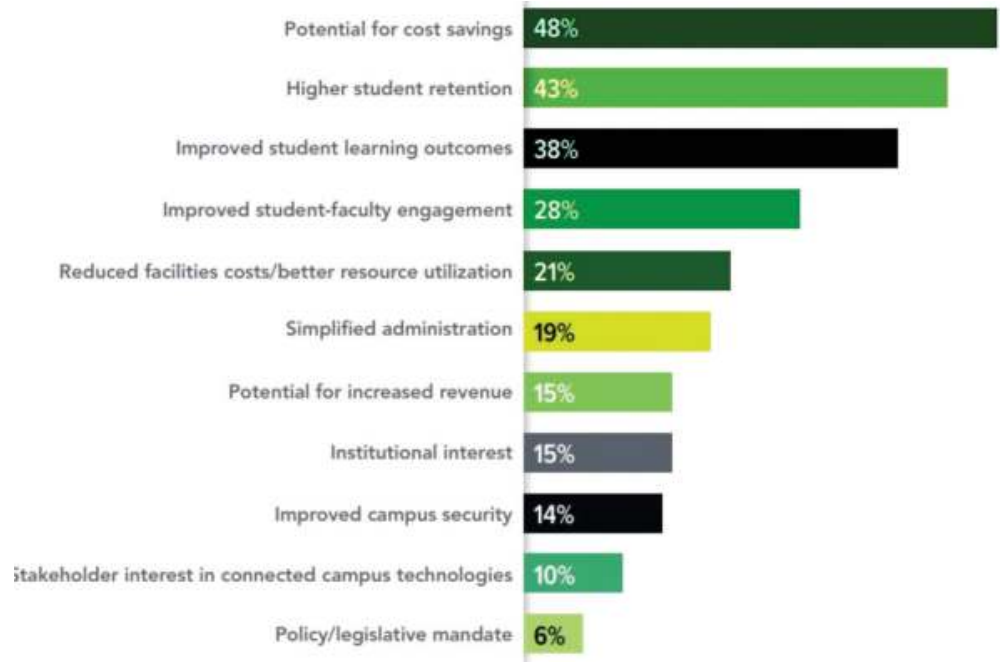

Figure 4. Driving factors for connected campus: CDE 138 higher education. [12].

\subsection{Preparation for IOT in i-campus}

To incorporate intelligence in campus using smart technologies for classrooms, all located within a smart campus required most reliable and very high-computing efficiency campus infrastructure. Only $23 \%$ believe their existing computing can able to sustain it in connected devices for campus activities. Then $36 \%$ believed that infrastructure would improve next year, but not a regular basis. Then $22 \%$ accepted as their infrastructure as of current state not adequate to do i-campus model.

So performance computing 4 out of 10 institutions which are $39 \%$ is required for improvements in the bandwidth of campus networks. Around 36\% need network booster to improve data analytics and higher cybersecurity. Almost thirty-three expected to increase their cloud infrastructure model. Relatively 3 out of 10 which are $28 \%$ as they do not know about what technologies are required for their campus. [12] So still it does not convey as they are unconcerned or indifferent. Some likely as individual's users working for shadow IT operations. But still many are lagging in broader understanding about institutional infrastructure requirements, even though they are capable to deploy connected devices for their campus to deliver services for all the stakeholders.

Many of this expected provision are cost investment for campus's technologies toward cyber security as highly needed for their demands. 19\% says about data analysis in decision-making, 17 for network infrastructure platform (Figure 5).

\subsection{Applicatioxn of IoT in industry}

\subsubsection{Smart home}

Smart home clearly opts out to be the odd technology out, seeming to overtake another breed of the Internet of Things applications as the topmost rank comparing all measured channels. 


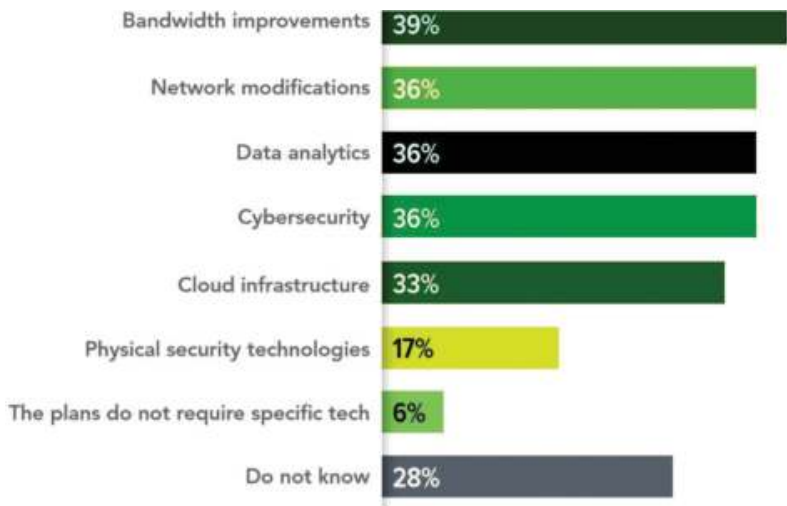

Figure 5. Technologies required for connected campus: CDE 138 higher education. [12].

The numbers of people are currently searching for the term 'Smart home 'seems to be increasing every month. A surprise whooping people of about 60,000 plus and odd keep searching the internet for the term the total revenue invested for Smart Home startups funding is a whopping amount which greatly exceeds $\$ 2.5$ billion.

The prominent startups which are involved in IoT-based applications are Nest or Alert Me. The MNC's which are involved in IoT-based applications are Philips, Haier or Belkin. A Data Analytics survey for the database for Smart Home includes 256 companies and startups. More companies which are more active in the smart home than any other applications in the field of IoT are huge in number.

\subsubsection{Wearables}

The wearable's remains seem to be the talk of the ICT Revolution. Among all the IoT startups, wearable's maker Jawbone is the biggest game player funding to date in the development process, accounting for about more than half a billion dollars as of today's market.

The Apples' new smartwatch is about to be released in April 2015. The consumers eagerly wait for the same: and there are plenty of stakes to unearth: like the Sony Smart B Trainer, the Myo gesture control, or Looksee bracelet... As consumers, there are plenty of other wearable innovations to be excited about: like the Sony Smart B Trainer, the Myo gesture control, or Looksee bracelet.

\subsubsection{Smart city}

The Smart city project initiatives by the Government spans a wide range of opportunities of use cases, from traffic management, water distribution, green buildings, urban security, environmental monitoring, Waste management techniques, Eco - friendly initiatives, Pollution restriction issues, Urbanization issues and Wastewater management Techniques. The innovative techniques in the most popular Smart City Solutions lay a strong emphasis on the fact to alleviate the atrocious pains of the people living in the cities. The IoT solutions in the area 
of Smart Cities solve Traffic Congestion problems in reducing noise and pollution levels and help make the cities safer.

\subsubsection{Smart grids}

The era now is into the Smart grids. On the establishment of a Smart, the grid emphasizes on the information application about the behaviors of the electricity suppliers, consumers, mediators and the flow analysis. The process of improving the efficiency is based on economic usage of electricity, reliability and improvisation density. The number of hits and Google documents after the semantic infusion reaches new heights. But the tweets, density seem to be very low in the case of smart grids, giving a descending correlation of the above-mentioned technology.

\subsubsection{Industrial internet}

The Internet is an integral part of routine comes from Industrial Internet which is one of the special Internet of Things applications. There are a number of Market Researchers such as Gartner or Cisco with the Industrial Internet IoT Concept bagging the overall potential. The Industrial Internet has got the highest number of tweets in Social Media compared to other non - consumer applied IoT concepts. The tweets per month account around 1700. It is not as much popular as the smart home or the wearables. It has got a very long way to reach the domestic market.

\subsubsection{Connected car}

There is a very slow process in the connected car. In spite that there is a very slow approach, the fact that the development of cycles in the Automotive Industry to make this fact come into reality, take at least a minimum of 2-4 years. BMW's and Fords of this world should start to foray into the market. If this does not happen at the present, then the next generation of Internet connected cars should soon be taken up by other well-known giants such as Google, Microsoft, and Apple which has announced its own Connected Car platforms [13].

\section{Smart connected campus}

The IoT connected the device in some institution has its presence over campuses. Such institutes have found the way to bridge the gap for new sources of data for improving their data analysis by building potential infrastructure platform which will differentiate from the way student's skill improvement, faculty smart campus utilization, non-teaching like administrators data management, academic scholars and every other stakeholder in i-campus.

\subsection{Research question}

Research issues identified in this article are about for possibilities findings the solution to the list of question given below to get better understanding of the article purpose and findings to society 
- Is it i-campus (IoT-enabled infrastructure for the campus.) need of the hour?

- Whether all academic institutes are equipped with high-end configuration technologies?

- Students provided all training and skill oriented facilities for regular teaching only?

- Whether all classrooms in every educational organization looking to upgrade to connected devices?

- All stakeholders from the educational field are aware of the need to upgrade their campus with modern technologies?

- IoT application's growth in industry market will have an impact in the educational sector?

- Is it needed to move on from regular blackboard teaching mode to gamification-based learning?

- Learning made easy by using gamification?

- Octalysis - gamification framework state importance of gamification learning?

- Is needed for gamification for the campus in teaching and learning?

So this IS interesting fact for innovation of many connected devices to the campus. So IoT expectation helps to engage the students and educate them more efficient manner, also reduce function operational costs and helps to improve security model on the campus. Institutions also gain many advantages, so major factors are to put building infrastructure in place which will support for smart technologies.

\subsection{Applications of IoT}

- Smart home

- Wearable's

- Connected cars

- Industrial internet

- Smart cities

- IoT in agriculture

- Smart retail

- Energy engagement

- IOT in healthcare

- IoT in poultry and farming

- i-Campus (IoT in smart campus)

- Medical field 
- Retail market

- logistics for supply chain

- Transportation

- Insurance with automation

- Energy management and distribution

- Cyber security

- Smart home automation

- The environmental monitoring

- Manufacturing, automobile industry

- Agriculture field

- Education for the e-learning domain

- Telecommunications

\section{3. i-Campus benefits}

The advancements on IoT in smart campus have enormous advantages. For all campus users like students and teachers, administrators all are new to this technology usage because they are not aware of this earlier. By using technology advancement students can be monitored and each other's too. It helps to utilize efficient energy consumption and also reduce energy burning for a range of all resources utilized within campuses for saving energy.

Automated lighting system and from air conditioner energy saving. The precise value of metering from resource utilization using sensors and institute has to pay as per resources being used. Education quality improvement: the IoT used in education field not only have a key impact in that field and also helps to improve the quality of the education. As millions of students studying global level at every college campus are fitted by this technology advancement [14].

In the near future, this goes to be a new trend in quite a large scale with IoT supported infrastructure build, So even rural students can able to be part of this global level accessibility of smart campuses which will uphold their life with highly skilled people in global market demands as changes in need according to scope of ROI in real markets [14].

Security is also a main concern due to the data breach occurrence every giant software application provider. So IoT-based i-campus may be exposed to large range possibilities of attacks. Hence Security model of i-campus highly concerned issues first among all other major functionalities. Smart Campus Challenges like stakeholders, members should be skilled, with more guidance able to deploy all devices with functionally capable, Sharing among the teacher for best practices, To engage all stakeholders among interested users, address all potential issues among iot project application approaches [15]. 


\subsection{Smart campus expectations}

- Transferring knowledge to others

- Technology dispersion among all

- Benefits of the stakeholder in long-term focus

- Smart campus enhances the skilled employee to produce a smart society

- Student success ratio by using i-campus

- Smart infrastructure for indoor and outdoor games

- Highly secured physical space on campus

- Connected smart vehicles

- Challenges on a the campus-like way of handling huge data

- Challenges in network security operation

- Usability among all users

- The project tracking and mentoring

- Mentoring and mentoring for research work

- To engage researchers

- Faculty mentoring

- Connected Device Management

- Inventory management of devices

- Guidelines for mobile devices in i-campus

- Infrastructure is supporting owned IoT devices from BYOD.

\subsection{Gamification: educational point of view}

How we can gamily educate in our classroom: So many educators are testing gamification learning in the classroom and getting a good positive outcome. A wide variety of learning available introduces ant classroom on basis of gamification.

Some of the gamifying education as listed here for learner's understanding and gamification objective is to make learners highly engaged [16].

- Gamily using awards and grade, Students awarded the using badge.

- Educational video games integrated into our syllabus.

- Blend users using to gamily competition [16] 
Games have many elements that make them powerful vehicles for human learning. They are commonly structured for players solve a problem; an essential skill needed for today and tomorrow. Many games promote communication, cooperation, and even competition among players. Some of the most immersive games have a rich narrative that spawns creativity and imagination in its players. Finally, depending on how they are designed, games can both teach and test their players. They are incredible packages of teaching, learning, and assessment [17].

\section{5. "Futurus" i-campus for e-learning model}

In the Internet of Things domain, rapid development is happening. So in the digital era, a college campus should be part of IoT technology enhanced infrastructure. All institutes campuses are lagging for utilization modern devices in e-learning platform. i-Campus (IoT in Smart Campus) future is going to be the drastic difference for students to enhance their learning skill from i-campus. Smart campus using ANN-Cumulative Dragonfly based training secured marks pattern to predicted new marks with rmse of 4.66 for improving the student's performance using neural network learning model also helps to build a modern smart campus for increased focus on student's growth using new technologies [18].

\subsection{IoT-enabled e-learning and its importance}

The Internet of Things (IoT) is used for sensing nearby location efficiently for data collection from various functionalities. Multiple inter-connected devices are able to form a chain of networks. i-Smart campus formation is possible for data collection using the device for the e-learning platform. The IoT platform is sharing information using M2M, M2 human, M to Mobile.

The IoT intelligently connects humans, devices and systems. Analysts describe two distinct communications in the IoT: thing to the person and thing-to-thing communication. [19] Communication from the machine to the human using a mobile device, connected devices to share and collect data from endpoints for the e-learning platform. The enhanced classroom for data collection is to store data on the digital platform in e-learning application. Learning platform created using IoT technology will have an impact on the user's engagement and ability to create curiosity among students for enthralling learning experiences using the smart classroom.

\section{2. i-Campus under single platform functionality}

Campus under Single platform functionality can be combined using many smart things collectivities in a single model platform like following

- e-Learning Application incorporated the IOT platform.

- IOT enabled the smart classroom, Advanced LAB Room uses IoT 
- Sensor for subjects, notes distribution, Sensor with Mobiles Devices and application

- Hotspot for campus with the highest configuration

- Possible potential services for future IOT campus accessible using connected devices for connection between things for integration of e-learning platform [20].

\subsection{Significance of using smart classroom in e-learning model}

- Every user is able to share notes using modern classroom's connected devices.

- The teacher can able to share notes with all students using an e-learning application which is easily assessable.

- Blended learning uses the smart classroom; Institutes Progress is on the next level.

- Allow the teacher to numbers of students makes like single classroom like virtual.

- Highly potential to expand its next level for teachers is to reach every student.

- Competitiveness among all others campuses due to localization connected devices.

- It enhances communication among users. In a single instance to send a notification to all users. Free accessible notes to all users [20].

\subsection{Enhancement of connected IoT devices for the smart classroom}

- Smart Board \& e-note's, New Communication model

- Classroom Monitoring, Collaborating with multiple classrooms

- Energy utilization, BYOD Gadgets in the smart learning platform

- Data Traffic in the network, Interoperability of multiple devices in IoT [20]

\section{IoT-based e-learning application model}

e-Learning platform model helps to understand infrastructure setup requirements and communication model among all entities in architecture. Below listed features are about possibilities to build new functionalities in every communication model set up like adding AR, 3D Visual in learning, Smartboard, Most compatible mobile application, new AI objects to e-learning platform etc. [21] All listed proposing new models such as 1) Augmented reality for IOT smart campus, 2) 3D objects based learning using IOT. 3) Display Board with IOT, 4) A mobile application with IoT platform data collection. 5) New Intelligent objects.

Architecture model depicts connected device setup for note's sharing in e-learning model for any college campus to build i-campus. This is one of the communication models among teachers, students and administrators. Data collection in IoT-enabled campus and sharing that among users using IoT in i-campus (Figures 6 and 7). 


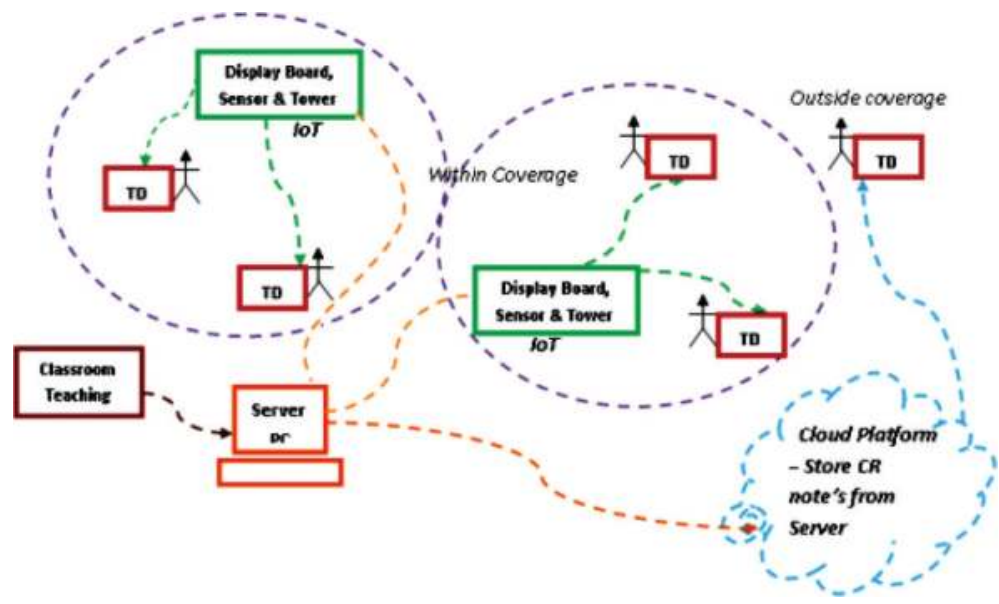

Figure 6. Note's sharing medium using IoT in i-campus.

Data model flow depicts flow in the complete model to smart campuses. This implementation works in favor of the new trend in demand market to allow everyone upgrade campus setup. This sharing data from one endpoint to another endpoint in network setup using iot build infrastructure. The classroom learning platform generates notes and carrying on sharing the medium with iot and accessible among end users students through a mobile application at the endpoint (Figure 8).

This implementation setup on the part of i-campus model explains the possibility of making communication model for note's sharing among all stakeholders. i-Campus vision is building infrastructure for making a more efficient model with maximum connected devices on that platform. Here Raspberry Pi is used to communicate with application to collect data from classroom teaching and learning model.

MySQL DB implemented for e-learning application for students registration and users log in features. Connection deployed using Apache server and Raspberry Pi computing device.

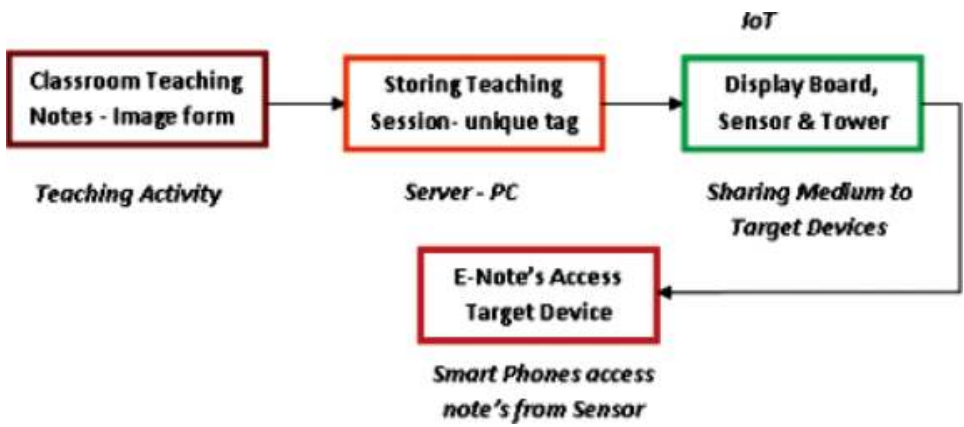

Figure 7. Classroom Note's sharing \& IoT -concept model. 


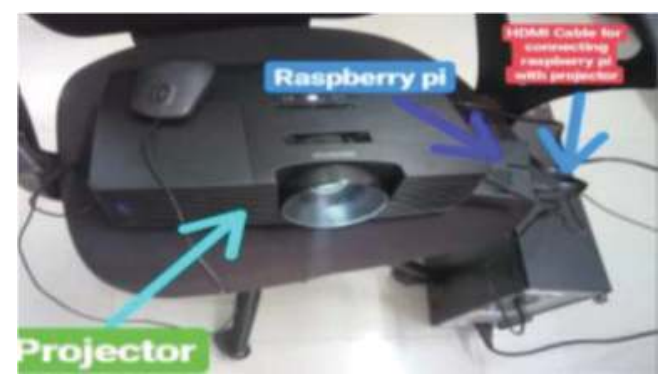

Figure 8. Smart Note's sharing in i-campus.

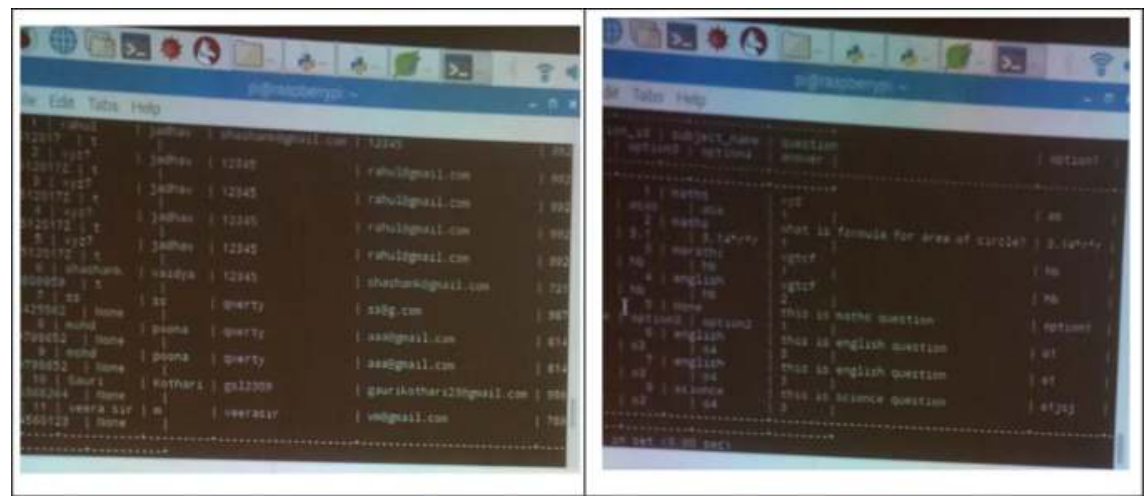

Figure 9. Database connection of notes sharing application in smart campus.

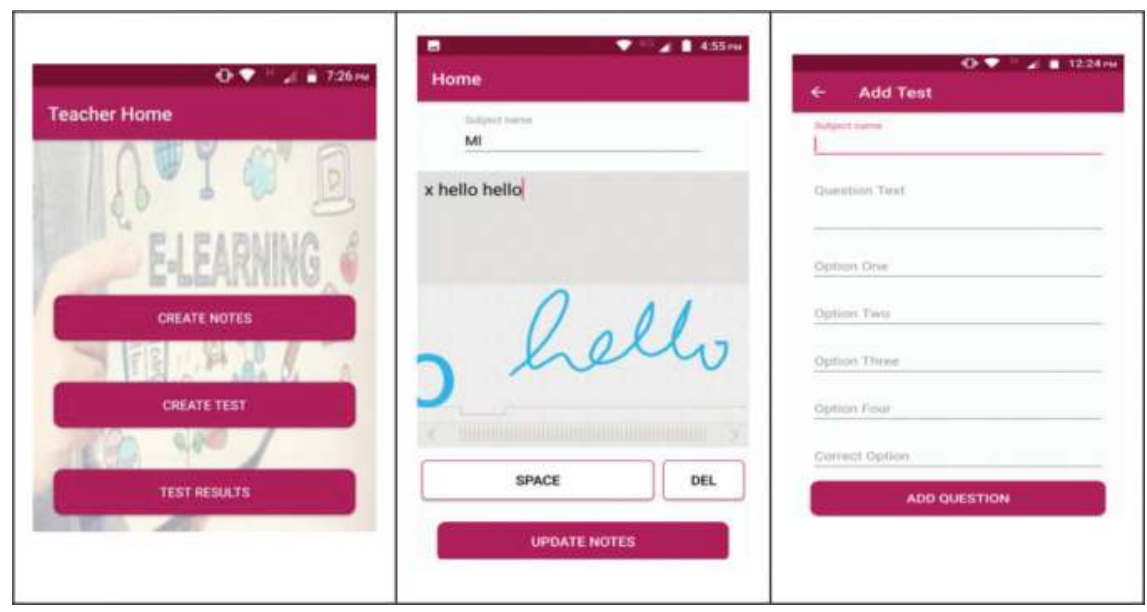

Figure 10. e-Learning application for notes sharing from smart campus. 
MCQ question added in MySQL Database and communications between entity connected using the Raspberry Pi device (Figures 9 and 10).

Smart e-learning application implemented and deployed within a campus location to visualize wisdom of i-campus in academic institutes. This application part of data sharing medium to bridge communication learners and trainers. Admin users can able to add new question sets for conducting assessment exam in online from the mobile application, allows users to download and use subject notes from the teacher's contribution notes material resources. The application provides a scribble screen to generate teacher's notes while teaching and allow them to upload it in the application for sharing among learners as its.

\section{Conclusion}

This chapter signifies the importance to an i-campus of an educational institution and the gamification learning mode of teaching and learning must be a part of the IoT-enabled campus. Research work given findings related two dimensions of educational fields, 1st perceptive about the need of IoT in campus, for enhanced technology availability for i-campus, which is realistic in the future and 2nd perceptive about better of engaging the student's effective learning using gamification. So many features are discussed, including smart classroom and gamification, notes sharing for knowledge transfer, online assessments using e-learning application; gamily helps to be competing among every learner. Hence it implies the importance of both methodologies for i-campus platform to makes learners for highly skilled oriented and efficient with smart learning environments.

\section{Author details}

Veeramanickam Murugappan ${ }^{1}$, Debnath Bhattacharyya ${ }^{2}$ and Tai-hoon Kim ${ }^{3 *}$

*Address all correspondence to: taihoonn@daum.net

1 Department of Computer Science and Engineering, Karpagam Academy of Higher

Education, Coimbatore, India

2 Department of Computer Science and Engineering, Vignan's Institute of Information Technology (Autonomous), Visakhapatnam, India

3 Department of Convergence Security, Sungshin W. University, Seongbuk-gu, Seoul, South Korea

\section{References}

[1] Are you ready for billions? https://www.hpe.com/in/en/solutions/internet-of-things.html 
[2] GSMA: The impact of the internet of things the connected home. https://www.gsma. com/newsroom/wp-content/uploads/15625-Connected-Living-Report.pdf

[3] Raising engagement in e-learning through gamification Cristina Ioana Muntean Cybernetics and Statistics, Babes-Bolyai University, Romania Strada Mihail Kogălniceanu, Nr. Cluj-Napoca, Ro

[4] C-H. Sumac-H. Cheng. A mobile gamification learning system for improving the learning motivation and achievements. JCAL on 6 Nov. 2014, DOI: 10.1111/jcal.1208

[5] Toward Personalized Gamification for Learning Environments Baptiste Monterrat, Élise Lavoué1, Sébastien George, France

[6] Simõesa J, DíazRedondo R, Vilas AF. A social gamification framework for a K-6 learning platform. Computers in Human Behavior. March 2013;29(2):345-353. https://doi. org/10.1016/j.chb.2012.06.007

[7] "An empirical study comparing gamification and social networking on e-learning", Joseba Saenz-de-Navarrete, Carmen Pagés. Computers \& Education, Volume 75, June 2014, Pages 82-91. https://doi.org/10.1016/j.compedu.2014.01.012

[8] Connolly TM, Stansfield M, Hainey T. An application of games-based learning within software engineering. 25 April 2007. DOI: 10.1111/j.1467-8535.2007.00706.x

[9] Gamification in education: Top 10 gamification case studies that will change our future, http://yukaichou.com/gamification-examples/top-10-education-gamification-examples/

[10] Amazing examples of gamification in education http://www.edsys.in/amazing-examplesof-gamification-in-education/

[11] Chou Y-K. Gamification \& Behavioral Design. http://yukaichou.com/

[12] Preparing for the connected campus: How and why institutions are using IOT. http:// www.centerdigitaled.com/paper/Preparing-for-the-Connected-Campus-How-andWhy-Institutions-Are-Using-IOT-92405.html

[13] Lueth KL. The 10 most popular internet of things applications right now, February 2, 2015, https://iot-analytics.com/10-internet-of-things-applications/

[14] Faga N. Internet of things promises smart future for campus infrastructure, utilities, building management and transportation fleets can reap benefits of connected systems, https://edtechmagazine.com/higher/article/2017/03/internet-things-promises-smartfuture-campus-infrastructure

[15] Beyond data in the Smart City: Repurposing existing campus IoT, by Oliver Bates and Adrian Friday, IEEE Pervasive Computing, Volume: 16, Issue: 2, April-June 2017

[16] Holloway S. 4 ways to bring gamification of education to your classroom. https://tophat. com/blog/gamification-education-class/

[17] 12 examples of gamification in the classroom. https://www.teachthought.com/the-futureof-learning/12-examples-of-gamification-in-the-classroom/ 
[18] Veeramanickam MRM, Mohanapriya M, Pandey BK, et al. Map-reduce framework based cluster architecture for academic student's performance prediction using cumulative dragonfly based neural network. Cluster Computing. 2018. https://doi.org/10.1007/ s10586-017-1553-5

[19] Dlodlo N, Foko T, Mvelase P, Mathaba S. The state of affairs in Internet of things research. The Electronic Journal Information Systems Evaluation. 2012;15(3):244-258

[20] Veeramanickam MRM, Mohanapriya M. IOT enabled futurus smart campus with effective E-learning: I-campus. GSTF Journal of Engineering Technology (JET). April 2016;3(4)

[21] Kavitha V, Lohani R. A critical study on the use of artificial intelligence, e-learning technology and tools to enhance the learner's experience. Cluster Computing. 2018. https:// doi.org/10.1007/s10586-018-2017-2 